\title{
Generic training will not prepare nurses of right calibre to care for children and families
}

THE SHAPE of Caring review was commissioned last year by Health Education England (HEE) and the Nursing and Midwifery Council (NMC) following a succession of high-profile publications (Willis 2012, Francis 2013, Keogh 2013, National Advisory Group on the Safety of Patients in England (known as the Berwick report) 2013, Bubb 2014).

These documents highlighted the need for patient-centred, compassionate and well-informed care. The Shape of Caring focuses on ensuring high quality care for the next 15 years achieved through consistent, high quality education for healthcare assistants (HCAs) and registered nurses.

The review was informed by a 'call for evidence' and a period of consultation, during which its chair Lord Willis met about 400 nurses $(0.6 \%$ of those on the register) in the NHS, third sector and higher education.

Shortly before the release of Shape of Caring, the UK Committee on Children and Young People's Nursing discussed the issues we expected to be raised. The committee, which is composed of leaders in children's nursing and health care from across the UK representing staff in the NHS, higher education and third sector, meets regularly to debate issues in children's and young people's (CYP) health care.

After its publication, the committee sent a letter to HEE raising a number of issues. Our main concern centred on the $2+1+1$ model of nursing education, which proposes a two-year generic preparation, followed by a specialist year to address field-specific learning, then one year of post-registration preceptorship.

The recommendation for the NMC to consider the future of the existing four fields model was a further concern, because it would potentially remove the opportunity for the next generation of nurses to undertake pre-registration preparation for CYP nursing. While we welcome some of the report's proposals, we have deep

\author{
UK Committee on Children and Young People's Nursing \\ members respond to the Shape of Caring proposals \\ to overhaul training of nurses in the UK
}

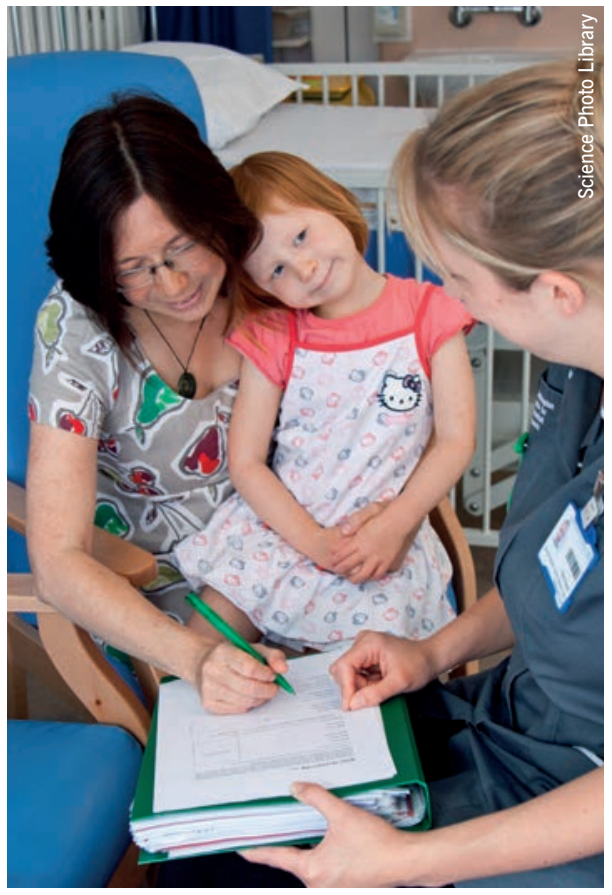

reservations about others. Our response focuses on the review's eight core themes.

Enhancing the voice of the patient and the public

Child health services have been developing innovative ways of engaging children and their families in service evaluation and research for many years. We have strong evidence about what children and parents want, supported by the Health Outcomes Forum (2015).

Other studies, based on listening activities, have made clear that children and families want nurses with appropriate skills, knowledge and experience to ensure they deliver safe and child-centred care.

\section{Valuing health care assistants}

Much of the care for children with chronic and complex needs is delivered by skilled HCAs who are much valued by the teams they work in, as well as the children and families they serve.

Ideally, there should be a care certificate tailored to the needs of infants, children and young people, based on the understanding that this approach is fundamental to safe care. Employers should be mandated to ensure that HCAs working with children complete this level of training.

Widening access for care assistants to enter nursing

Many opportunities for wider entry already exist. Indeed, students on nursing degrees are on one of the most diverse and inclusive undergraduate programmes. We welcome more opportunities to encourage individuals with the right attitudes, abilities and behaviours to undertake a tailored child health programme.

\section{Developing a flexible mode}

We have considerable reservations about the proposal that a period of generic preparation is sufficient to equip every nurse to care effectively for children and their families. We think that care is provided best by those who are educated and prepared specifically to nurse children.

Evidence from the survey undertaken as part of an evidence-gathering exercise (see panel) demonstrates that nursing students deliberately choose the field of practice they wish to study.

Assuring a high quality learning environment in undergraduate nursing education

We think that children's nurses need high quality preparation for their specific role in caring for children and their families; however, the environment must foster the skills necessary for caring for children. We have strong reservations about whether this 


\section{Evidence gathering}

In addition to responding to consultation on the Shape of Caring in writing, raising concerns about recommendations for nursing education, the UK Committee on Children and Young People's Nursing commissioned two evidence-gathering exercises.

UK survey of child field nursing students The poll was carried out between February and March this year and more than 800 nurses responded. It included the following questions:

- 'Was children's nursing your first choice when you decided to commence nurse training?'

The response was a resounding 'yes' (98.3\%). Of those who responded, $77 \%$ had not considered another field of nursing. Of the $33 \%$ who had done so, $77 \%$ had considered adult nursing. 'Would you have chosen to train as

can succeed in the proposed 2+1+1 model, where more emphasis and resources are likely to be centred on 'adult-oriented' care.

Assuring predictable and sustainable access to ongoing learning and development for registered nurses Universities, employers, regulators, professional bodies and commissioners should work together to build on existing preceptorship standards to explore the development and implementation of a specific year-long preceptorship programme for newly qualified registered children's nurses.

In principle, there seems to be little to argue against in this recommendation. However, we raise concerns about the potential for such a programme to be generic. Nurses caring for children must have access to a specific child-

\section{Find out more}

Raising the Bar. Shape of Caring: A Review of the Future Education and Training of Registered Nurses and Care Assistants. tinyurl.com/q8wrttv a nurse if you had not been able to choose children's nursing?' Of those responding, 50\% said 'no'. A total of $98 \%$ of respondents said they intended to work as a children's nurse once they had registered.

\section{Freedom of Information Act request} The committee contacted 77 higher education institutions to ascertain attrition rates for undergraduate nursing students, of which 43 responded and provided figures. The information revealed that:

- The average rate in children's nursing is $5.88 \%$, which compares favourably against the average in adult nursing of $11.71 \%$.

The highest attrition rate of $28 \%$ was found in mental health nursing in one institution. The highest in adult nursing in an institution was $25 \%$.

oriented preceptorship programme to support their development as children's nurses and meet the requirements of periodic revalidation.

Supporting and enabling research, innovation and evidence-based practice Children's nursing has a blossoming research base and more activity in this area would enhance the evidence base for high quality, safe and effective care offered to children and their families.

There is every expectation that nursing research would improve the outcomes of child health. However, changes to the four fields model of education and registration could threaten the future of child health research.

\section{Assuring high quality funding and commissioning}

The CYP community agrees with the recommendation that HEE should review commissioning and funding mechanisms to explore whether a more multiprofessional skill mix/population-based approach should be developed for education and training.

Children's nurses do not exist in isolation and they work with GPs, paediatricians, teachers, social workers and the third sector.

There are myths and fallacies that influence the commissioning of children's nursing, for example, that there is a higher attrition rate in pre-registration education programmes than in the other fields.

However, our Freedom of Information Act requests revealed that attrition across the branch programmes varies, with the highest found not in children's nursing but in mental health nursing (see panel).

During discussions about the Shape of Caring review children's nurses have repeatedly referred to the "child health nurse' model developed by the RCN's Children and Young People's Field of Practice (2007) following a summit and series of networking events.

We propose a two-pathway approach to registration, each encompassing mental health, public health and learning disabilities. One would be child health and the other adult and older people's nursing, providing whole-person care as described by Lord Willis. It would also provide a robust preparation of nurses to meet the needs of infants, children and young people with acute or long-term conditions across all settings.

Bernie Carter is professor of nursing, University of Central Lancashire, and director of the children's nursing research unit, Alder Hey NHS Foundation Trust, Liverpool; Dave Clarke is senior lecturer in nursing, Cardiff University; Doreen Crawford is senior lecturer in nursing and midwifery, De Montfort University, Leicester, and consultant editor, Nursing Children and Young People; Fiona Smith is RCN professional lead for children and young people's nursing

\section{References}

Bubb S (2014) Winterbourne View - Time for Change. tinyurl. com/mj7uz7v

Francis R (2013) The Mid-Staffordshire NHS Foundation Trust Public Inquiry. tinyurl.com/p2ebw82

Health Outcomes Forum (2015) Report of the Children and Young People's Health Outcomes Forum 2014/15. tinyurl.com/ q8v4dok

Keogh B (2013) Review into the Quality of Care and Treatment Provided by 14 Hospital Trusts in England: Overview Report. tinyurl.com/p3cypjn

National Advisory Group on the Safety of Patients in England (2013) A Promise to Learn - A Commitment to Act. Improving the Safety of Patients in England. tinyurl.com/q6a7zkh

RCN Children and Young People's Field of Practice (2007) Preparing the Child Health Nurse - Fit for the Future. tinyurl. com/pe7n6xj

Willis Commission (2012) Quality wiht Compassion: the Future of Nursing Education. tinyurl.com/cvugp8t 